\title{
Metabolic modeling of Chlamydomonas reinhardtii: energy requirements for photoautotrophic growth and maintenance
}

\author{
Anna M. J. Kliphuis • Anne J. Klok • Dirk E. Martens • \\ Packo P. Lamers • Marcel Janssen • René H. Wijffels
}

Received: 5 November 2010 / Revised and accepted: 24 February 2011 / Published online: 15 April 2011

(C) The Author(s) 2011. This article is published with open access at Springerlink.com

\begin{abstract}
In this study, a metabolic network describing the primary metabolism of Chlamydomonas reinhardtii was constructed. By performing chemostat experiments at different growth rates, energy parameters for maintenance and biomass formation were determined. The chemostats were run at low irradiances resulting in a high biomass yield on light of $1.25 \mathrm{~g} \mathrm{~mol}^{-1}$. The ATP requirement for biomass formation from biopolymers $\left(K_{x}\right)$ was determined to be $109 \mathrm{mmol} \mathrm{g}^{-1}$ $\left(18.9 \mathrm{~mol} \mathrm{~mol}^{-1}\right)$ and the maintenance requirement $\left(m_{\text {ATP }}\right)$ was determined to be $2.85 \mathrm{mmol} \mathrm{g}^{-1} \mathrm{~h}^{-1}$. With these energy requirements included in the metabolic network, the network accurately describes the primary metabolism of $C$. reinhardtii and can be used for modeling of C. reinhardtii growth and metabolism. Simulations confirmed that cultivating microalgae at low growth rates is unfavorable because of the high maintenance requirements which result in low biomass yields. At high light supply rates, biomass yields will decrease due to light saturation effects. Thus, to optimize biomass yield on light energy in photobioreactors, an optimum between low and high light supply rates should be found. These simulations show that metabolic flux analysis can be used as a tool
\end{abstract}

Anna M.J. Kliphuis and Anne J. Klok contributed equally to this paper.

Electronic supplementary material The online version of this article (doi:10.1007/s10811-011-9674-3) contains supplementary material, which is available to authorized users.

A. M. J. Kliphuis $(\bowtie) \cdot$ A. J. Klok $\cdot$ D. E. Martens $\cdot$

P. P. Lamers $\cdot$ M. Janssen $\cdot$ R. H. Wijffels

Bioprocess Engineering, Wageningen University,

P.O. Box 8129, 6700 EV, Wageningen, The Netherlands

e-mail: Annette.Kliphuis@gmail.com

URL: www.algae.wur.nl

A. J. Klok

e-mail: Anne.Klok@wur.nl to gain insight into the metabolism of algae and ultimately can be used for the maximization of algal biomass and product yield.

Keywords Energy requirements · Metabolic flux analysis (MFA) - Chlamydomonas reinhardtii · Maintenance - Yield . Respiration

\section{Nomenclature}

$\mu \quad$ Specific growth rate $\left(\mathrm{h}^{-1}\right)$

$\Sigma q_{i}{ }^{\mathrm{ATP}} \quad$ Specific ATP production rate in the metabolism with known ATP stoichiometry ( $\mathrm{mmol} \mathrm{g}^{-1} \mathrm{~h}^{-1}$ )

$\Phi_{\mathrm{P}} \quad$ Photochemical quantum yield (-)

$\Phi_{\text {Pmax }} \quad$ Maximum photochemical quantum yield (-)

A Transpose of the stoichiometric matrix of the network (-)

$A_{\mathrm{pbr}} \quad$ Illuminated surface of the photobioreactor $\left(\mathrm{m}^{2}\right)$

$C_{x} \quad$ Biomass concentration in the photobioreactor $\left(\mathrm{g} \mathrm{L}^{-1}\right)$

$K_{x} \quad$ ATP requirement for the formation of biomass from biopolymers ( $\mathrm{mmol} \mathrm{g}^{-1}$ or $\mathrm{mol} \mathrm{mol}^{-1}$ )

$m_{\text {ATP }} \quad$ Maintenance ATP requirements ( $m$ mol ATP $\mathrm{g}^{-1} \mathrm{~h}^{-1}$ )

$m_{E} \quad$ Maintenance light energy requirements ( $\mathrm{mmol}$ photons $\mathrm{g}^{-1} \mathrm{~h}^{-1}$ )

$N \quad$ Number of measurements (-)

$\mathrm{OD}_{530} \quad$ Optical density measured at $530 \mathrm{~nm}$ on a spectrophotometer $(-)$

PFD Photon flux density ( $\mu$ mol photons $\mathrm{m}^{-2} \mathrm{~s}^{-1}$ )

$\mathrm{PFD}_{\text {abs }}$ Average photon flux density absorbed by the microalgal culture ( $\mu \mathrm{mol}$ photons $\mathrm{m}^{-2} \mathrm{~s}^{-1}$ )

$q_{\text {ATP }} \quad$ Total specific ATP production rate in the metabolism $\left(\mathrm{mmol} \mathrm{g}^{-1} \mathrm{~h}^{-1}\right)$

$q_{\text {ATP, }} \quad$ Specific ATP production rate in the chloroplast light $\quad\left(\mathrm{mmol} \mathrm{g}^{-1} \mathrm{~h}^{-1}\right)$

$q_{\text {ATP,ox }}$ Specific ATP production rate in oxidative phosphorylation $\left(\mathrm{mmol} \mathrm{g}^{-1} \mathrm{~h}^{-1}\right)$ 
$r_{\text {Ex }} \quad$ Specific light supply rate (mol photons $\mathrm{g}^{-1} \mathrm{~h}^{-1}$ )

$r_{\mathrm{Ex}, \mu} \quad$ Specific light utilization rate (mmol photons $\mathrm{g}^{-1} \mathrm{~h}^{-1}$ )

$V_{\mathrm{pbr}} \quad$ Working photobioreactor volume (L)

$Y_{x \text { ATP }} \quad$ Yield of biomass on ATP $\left(\mathrm{g} \mathrm{mol}^{-1}\right)$

$Y_{x E} \quad$ Biomass yield on light energy $\left(\mathrm{g} \mathrm{mol}^{-1}\right)$

$Y_{x E}$ obs Observed experimental biomass yield on light energy, not corrected for maintenance requirements $\left(\mathrm{g} \mathrm{mol}^{-1}\right)$

\section{Introduction}

Microalgae are interesting organisms because of their ability to produce a wide range of compounds, such as carotenoids (Ben-Amotz et al. 1982; Kleinegris et al. 2010; Lamers et al. 2008), lipids (Chisti 2007; Hu et al. 2008; Griffiths and Harrison 2009), hydrogen (Ghirardi et al. 2000; Melis et al. 2000), protein (Boyd 1968; Becker 2007), and starch (Delrue et al. 1992). These algal compounds have numerous applications, varying from fine chemicals to biofuels to food additives. To make commercial bulk production of these compounds economically feasible, maximization of algal biomass production and optimization of biomass composition are necessary. Understanding of how compounds are produced in the algal metabolism will help to fully exploit the potential of microalgae and their products.

Metabolic flux analysis (MFA) is a powerful tool to study the fluxes through metabolic pathways of any organism of interest. It provides information on how nutrients and energy are utilized to form biomass and other components. Using information on metabolic fluxes and pathways, a better understanding of metabolism is obtained, and targets for process optimization or genetic modification can be identified. Several metabolic network models have been published for common production organisms, such as Escherichia coli (Carlson and Srienc 2004; Kayser et al. 2005), Saccharomyces cerevisiae (Forster et al. 2003), and Corynebacterium glutamicum (Kieldsen and Nielsen 2009). Due to the increasing interest in microalgae as production organisms, metabolic networks for photoautotrophic organisms such as Chlorella vulgaris (Yang et al. 2000) and Arthrospira (Spirulina) platensis (Cogne et al. 2003) have been developed as well. Metabolic flux analysis will improve understanding of algal metabolism and ultimately can be used for the maximization of algal biomass and product yield (Schmidt et al. 2010).

Chlamydomonas reinhardtii has been studied extensively in the past decades. It is regarded as a model organism for green microalgae because of its diverse metabolism and its ability to grow photoautotrophically as well as heterotrophically on acetate (Gfeller and Gibbs 1984; Heifetz et al. 2000). In addition, $C$. reinhardtii is able to accumulate starch (Ball et al. 1990) and produce hydrogen when grown

anaerobically (Melis et al. 2000). The Chlamydomonas genome has been sequenced (Merchant et al. 2007), and the availability of this genetic information provides a sound basis for the development of metabolic network models. Recently, Boyle and Morgan (2009) and Manichaikul et al. (2009) developed two extensive genome-scale models describing the primary metabolism of $C$. reinhardtii divided over several cellular compartments, and as such, both models have a high degree of compartmentalization. They qualitatively end up to a limited extent quantitatively predict algal metabolism and are well suited to get a better insight in algal metabolism. However, quantitative validation is very limited, and there are some difficulties in developing such detailed models. For a number of reactions, the localization is not known and has to be assumed. Also, information on the exchange of metabolites between compartments is limited. Finally, to reduce the number of fluxes that cannot be calculated, many, often complex, measurements are needed. When developing a metabolic model, the practical applicability should be considered. Extensive, fully compartmentalized models are excellent tools for the qualitative study of cellular reaction networks and their regulation but are generally not suited for quantitative studies because of their underdetermined characteristics. A model for finding specific engineering bottlenecks and solutions would call for simple, easy to handle networks, which require less input parameters and optimization commands but still represent the important characteristics of metabolism (Burgard et al. 2001). Therefore, we developed a more condensed metabolic model describing the primary metabolism of $C$. reinhardtii, in which reactions are less extensively compartmentalized and which is thus less underdetermined.

Apart from the abovementioned uncertainties on compartmentalization and transport steps, the stoichiometry of the energy metabolism is not fixed in these models. The amount of energy in the form of adenosine triphosphate (ATP) required for biomass formation and maintenance is difficult to determine and varies between different microorganisms and growth conditions (Pirt 1965). These parameters are essential in metabolic modeling because they largely influence the growth dynamics and biomass or product yields calculated by the model. It is known from previous studies that theoretical estimates of the amount of ATP used for the production of biomass based solely on the required energy for the formation of biopolymers is much lower than the experimentally determined value (Baart et al. 2008; Kayser et al. 2005; Roels 1983). Additional energy is required for the assembly of biopolymers into growing biomass. In order to obtain a correct metabolic network model, these parameters have to be determined experimentally.

In this paper, we describe the construction of a metabolic model for $C$. reinhardtii and the subsequent experimental determination of the energy requirements for maintenance 
and biomass formation. In this model, photosynthesis and the Calvin cycle are the only processes that are compartmentalized in order to separate these processes from the pentose phosphate pathway (PPP) in the cytosol and energy generation in the mitochondria. Furthermore, reactions in linear pathways are lumped. The energy parameters are estimated from a series of chemostats operated at different dilution rates, a commonly used method for heterotrophic microorganisms (Kayser et al. 2005; Taymaz-Nikerel et al. 2010). To the best of our knowledge, this has not been applied to photoautotrophically grown microalgae, most probably because light is a challenging energy source to measure accurately. This study shows how this method can be applied to determine energy parameters for photoautotrophic organisms. The final model including the determined energy parameters was used to calculate the respiration rate at different specific growth rates, which enabled prediction of optimal growth rates for efficient light use.

\section{Materials and methods}

C. reinhardtii CC1690 (Chlamydomonas Genetics Centre, Duke University) was cultivated in $250-\mathrm{mL}$ shake flasks containing $100 \mathrm{~mL}$ defined medium (Table 1) at $\mathrm{pH}$ 7.0. The medium was based on the Sueoka high salts medium, enriched for magnesium and calcium (Sueoka et al. 1967). Additional EDTA was added to prevent precipitation of salts. Nitrate was used as a nitrogen source and enough nitrogen was added to support $4.5 \mathrm{gL}^{-1}$ biomass. Finally, $1 \mathrm{~mL}$ of trace element solution was added to the medium. This trace element solution was based on Hutner's trace element solution (Hutner et al. 1950). The medium was sterilized by filtering through a Whatman liquid filter (pore size $0.2 \mu \mathrm{m}$ ) into a pre-sterilized medium vessel. The medium for the photobioreactor experiments was enriched with $5.00 \mathrm{mmol} \mathrm{L}^{-1} \mathrm{NaHCO}_{3}$ to ensure sufficient dissolved $\mathrm{CO}_{2}$ supply to the algae.
C. reinhardtii cultures were maintained in a culture chamber at $25^{\circ} \mathrm{C}$, an irradiance of $20-40 \mu \mathrm{mol}$ photons $\mathrm{m}^{-2} \mathrm{~s}^{-1}$ and a $16 / 8 \mathrm{hday} / \mathrm{night}$ cycle. To reach inoculation cell density, the cultures were placed in a shake incubator for 3 days at a continuous irradiance of $280 \mu \mathrm{mol}$ photons $\mathrm{m}^{-2} \mathrm{~s}^{-1}$ and a headspace enriched with $5 \%$ carbon dioxide.

\section{Reactor setup and experiments}

Chlamydonomas reinhardtii was cultivated in chemostat mode in a pre-sterilized flat panel photobioreactor. Dilution rates in a range of 0.018 to $0.064 \mathrm{~h}^{-1}$ were used. Figure 1 shows a schematic view of the experimental setup. The photobioreactor consisted of two transparent polycarbonate sheets held together by a stainless steel frame. The reactor had a working volume $\left(V_{\mathrm{pbr}}\right)$ of $0.4 \mathrm{~L}$, a light path of $25 \mathrm{~mm}$, and an illuminated area $\left(A_{\mathrm{pbr}}\right)$ of $195 \mathrm{~cm}^{2}(10 \times 19.5 \mathrm{~cm})$.

Using mass flow controllers (Brooks, Smart TMF SLA5850), the system was aerated with pressurized air at an airflow of $0.2 \mathrm{Lmin}^{-1}$. The $\mathrm{pH}$ was controlled at 7.0 \pm 0.2 by the automatic addition of $\mathrm{CO}_{2}$ to the airflow using a $\mathrm{pH}$ stat control system. This ensured that a sufficiently high concentration of $\mathrm{CO}_{2}$ was present in the medium during the cultivation, and the microalgae were only growing under light limited conditions. The temperature was maintained at $25^{\circ} \mathrm{C}$ by an external water bath.

Continuous illumination was provided by a red LED panel of $20 \times 20 \mathrm{~cm}$ (LED Light Source SL 3500, average optimum $630-365 \mathrm{~nm}$ and spectral half width of $20 \mathrm{~nm}$, Photon System Instruments, Czech Republic) placed on one side of the photobioreactor. An average irradiance of $<100 \mu \mathrm{mol}$ photons $\mathrm{m}^{-2} \mathrm{~s}^{-1}$ was used. The photon flux density (PFD) was measured with a LI-COR 190-SA $2 \pi$ sensor (PAR range $400-700 \mathrm{~nm}$ ) at 15 fixed points behind the reactor. The measured irradiances at all 15 points were averaged into a PFD for that particular experiment. During the experiments, the light falling through the culture was measured in the same way. The average photon flux density absorbed by the algal culture
Table 1 Composition of Chlamydomonas reinhardtii medium, designed to reach $4.5 \mathrm{gL}^{-1}$ biomass dry weight

$1 \mathrm{~mL}$ of trace element stock was added per liter medium. $\mathrm{NaHCO}_{3}$ was added to the medium for experiments in the photobioreactor

\begin{tabular}{lcllr}
\hline \multicolumn{3}{l}{ Medium } & & \multicolumn{2}{l}{ Trace element stock } \\
\cline { 5 - 5 } Compound & Concentration $\left(\mathrm{mmol} \mathrm{L}^{-1}\right)$ & & Compound & Concentration $\left(\mathrm{mmol} \mathrm{L}^{-1}\right)$ \\
\hline $\mathrm{KNO}_{3}$ & 24.73 & & $\mathrm{FeSO}_{4} \cdot 7 \mathrm{H}_{2} \mathrm{O}$ & 17.96 \\
$\mathrm{KH}_{2} \mathrm{PO}_{4}$ & 5.29 & & $\mathrm{Na}_{2} \mathrm{EDTA} \cdot \mathrm{H}_{2} \mathrm{O}$ & 148.69 \\
$\mathrm{~K}_{2} \mathrm{HPO}_{4}$ & 8.28 & & $\mathrm{ZnSO}_{4} \cdot 7 \mathrm{H}_{2} \mathrm{O}$ & 76.51 \\
$\mathrm{MgSO}_{4} 7 \mathrm{H}_{2} \mathrm{O}$ & 1.14 & & $\mathrm{H}_{3} \mathrm{BO}_{3}$ & 184.38 \\
$\mathrm{CaCl}_{2} 2 \mathrm{H}_{2} \mathrm{O}$ & 0.39 & & $\mathrm{MnCl}_{2} \cdot 4 \mathrm{H}_{2} \mathrm{O}$ & 25.57 \\
$\mathrm{Na}_{2} \mathrm{EDTA}_{2} \mathrm{H}_{2} \mathrm{O}$ & 0.18 & & $\mathrm{CoCl}_{2} \cdot 6 \mathrm{H}_{2} \mathrm{O}$ & 6.77 \\
$\mathrm{NaHCO}_{3}$ & 5.00 & & $\mathrm{CuSO}_{4} \cdot 5 \mathrm{H}_{2} \mathrm{O}$ & 6.29 \\
& & & $\left(\mathrm{NH}_{4}\right)_{6} \mathrm{Mo}_{7} \mathrm{O}_{24} \cdot 4 \mathrm{H}_{2} \mathrm{O}$ & 0.89 \\
\hline
\end{tabular}




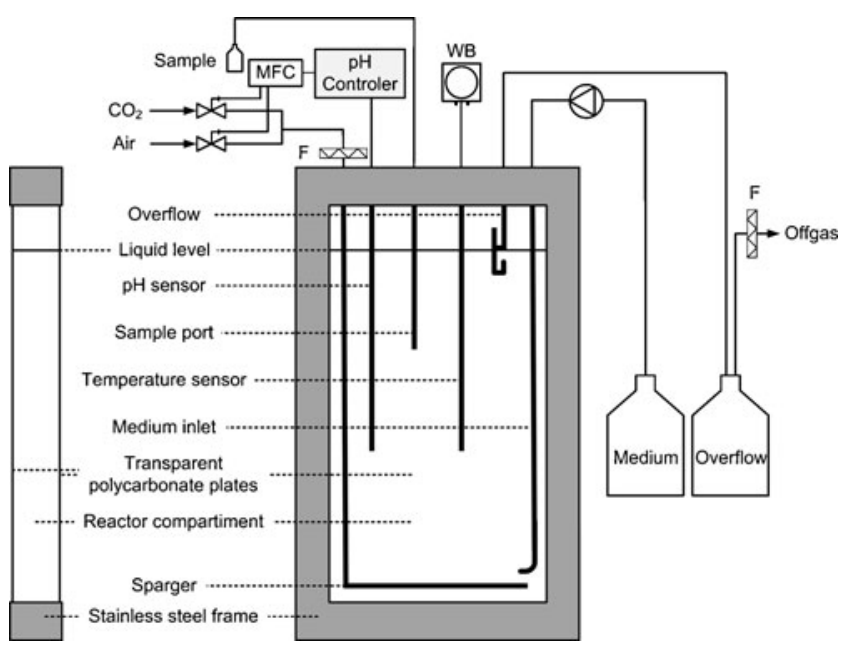

Fig. 1 Schematic front and side view of the photobioreactor setup (not on scale) for the chemostat experiments. $M F C$ mass flow controller for both air and $\mathrm{CO}_{2}, W B$ water bath, $F$ air filter

$\left(\mathrm{PFD}_{\mathrm{abs}}\right)$ could be calculated by subtracting the light falling through the culture at steady state from the amount of light falling through the reactor filled with medium only. The resulting value was corrected for the loss of light due to backscattering of light on the algal cells, for which a fixed loss of $2 \%$ was assumed (Pottier et al. 2005).

After inoculation at an optical density at $530 \mathrm{~nm}\left(\mathrm{OD}_{530}\right)$ of 0.05 , the culture was grown in batch mode until a sufficient optical density was reached. Then, the medium supply was started at a constant dilution rate until steady state was reached. In these experiments, steady state was defined as a constant optical density, biovolume, and cell density $\left(C_{\mathrm{x}}, \mathrm{g} \mathrm{L}^{-1}\right)$ in the photobioreactor for at least five residence times. Biomass samples were taken from the middle of the reactor or from the overflow, which was collected on ice. Both sample methods gave the same results. Due to the small reactor volume, it was necessary to take the larger samples for dry weight determination and biomass composition from the overflow in order to prevent disturbances of the steady-state equilibrium.

Cell number and cell size were determined in duplicate with a Beckman Coulter Multisizer 3 (Beckman Coulter Inc., USA, $50 \mu \mathrm{m}$ orifice). The samples were diluted with filtered $(0.2 \mu \mathrm{m})$ Coulter $^{\circledR}$ Isoton ${ }^{\circledR}$ II dilution buffer to a cell concentration between $1 \times 10^{5}$ and $3 \times 10^{5}$ cells $\mathrm{mL}^{-1}$. The cell number and cell size were used to calculate the total biovolume.

For dry weight determination, Whatman glass microfiber filters $(\theta 55 \mathrm{~mm}$, pore size $0.7 \mu \mathrm{m})$ were dried at $95^{\circ} \mathrm{C}$ overnight and placed in a desiccator to cool to room temperature. The empty filters were weighed and pre-wet with de-mineralized water. Two grams of sample were diluted with de-mineralized water and filtrated under mild vacuum. The filter was rinsed twice with de-mineralized water to remove adhering inorganic salts. The wet filters containing the samples were dried at $95^{\circ} \mathrm{C}$ overnight, allowed to cool to room temperature in a desiccator, and weighed. The dry weight of the samples was then calculated from the difference in weight between the dry filters with and without biomass.

To determine the biomass composition, liquid samples were centrifuged for $10 \mathrm{~min}$ at $1750 \mathrm{RCF}$, and the resulting pellets were washed three times with de-mineralized water by re-suspending and centrifuging and stored at $-20^{\circ} \mathrm{C}$. Algae pellets stored at $-20^{\circ} \mathrm{C}$ were freeze-dried and ground to a fine powder. The freeze-dried algae powder was used for all further biomass composition analyses. Ash content was determined by burning the freeze-dried algae samples in an oven at $550^{\circ} \mathrm{C}$, so that all organic material was oxidized and the ash residue remained.

Lipid content was determined gravimetrically after extraction of the freeze-dried algal powder with a 5:4 methanol/chloroform mixture as described by Lamers et al. (2010). The resulting total lipid extract contained all lipidlike compounds present in the algal cells, including pigments. Therefore, the weight of the total lipid extract had to be corrected for the amount of pigments present. Pigments were determined spectrophotometrically after dissolving the lipid residue in methanol. The total pigment content was calculated using absorption equations for chlorophyll in methanol (Porra 2002). The relative fatty acid composition was determined by GC analysis according to the method described by Bosma et al. (2008).

Carbohydrates were measured by treating the freezedried algae powder with a phenol solution and concentrated sulfuric acid, according to Dubois et al. (1956) and Herbert et al. (1971). The absorbance of the resulting solution was measured at $483 \mathrm{~nm}$. Pure glucose was used as a standard.

The nitrogen content of the biomass was determined on a Flash EA 1112 Protein Analyzer (Thermo Scientific, USA). To calculate the amount of protein from the nitrogen content, a $\mathrm{N} /$ protein conversion factor of $4.58 \pm 0.11$ was used (Lourenço et al. 1998). This factor was determined specifically for several microalgal species at different growth phases.

The relative amino acid composition was determined by Ansynth Service BV (Berkel en Roodenrijs, The Netherlands), using classical ion-exchange liquid chromatography with post-column ninhydrin derivatization and photometric detection. Proteins were hydrolyzed by acid hydrolysis prior to column injection. Cysteine, methionine, and tryptophan were determined separately. Cysteine and methionine were measured by oxidation followed by acid hydrolysis, and tryptophan by alkaline hydrolysis followed by reverse phase HPLC.

The nucleic acids DNA and RNA were not measured directly but were calculated from cell number data. From 
the amount of different nucleotides in $C$. reinhardtii (Merchant et al. 2007), it could be calculated that each cell contains $1.3 \times 10^{-13}$ g DNA per cell. RNA was assumed to be present in a 28 -fold higher concentration than DNA. Valle et al. (1981) determined this ratio RNA/DNA for $C$. reinhardtii by measuring DNA and RNA contents at various cell concentrations, by means of a fluorometric determination.

Flux balancing

The metabolism of an organism can be described by a set of reaction equations defining the stoichiometric conversion of substrates into products (Stephanopoulos et al. 1998). The stoichiometry matrix $S$ contains the stoichiometric coefficients of the substrates and products for the different reactions in the metabolic network, which also includes the transport reactions over the membranes. To be able to calculate fluxes, mass balances are written for all the intracellular metabolites present in the network. Assuming steady state and neglecting the accumulation of intermediates, this results in the next set of linear equations:

$A \cdot x=0$

in which $A$ is the transpose of the stoichiometry matrix $S$ and $x$ is the vector which contains the reaction rates.

The solution space of Eq. 1 was studied to find possible dead ends in the model, which were subsequently removed.

Because part of the rates in $\mathrm{x}$ is usually measured, Eq. 1 can be converted to:

$A_{\mathrm{c}} \cdot x_{\mathrm{c}}=-A_{\mathrm{m}} \cdot x_{\mathrm{m}}$

where $x_{\mathrm{c}}$ contains the unknown and $x_{\mathrm{m}}$ contains the measured rates. $A_{\mathrm{c}}$ and $A_{\mathrm{m}}$ are the corresponding parts of the matrix $A$. By studying the null space of $A_{\mathrm{c}}$, it was revealed that our system was underdetermined; therefore, no unique solution of Eq. 2 exists. Underdeterminancies were solved by setting constraints to some of the fluxes in the underdetermined part of the metabolism and using optimization of an objective function. Thus, linear programming/ optimization was used according to Eq. 3:

$$
\begin{array}{ll}
\text { Objective function : } & \max (c \cdot x) \\
\text { Constraints : } & A \cdot x=0 \\
& \mathrm{LB} \leq x \leq \mathrm{UB}
\end{array}
$$

in which c contains the objective function, and LB and UB are the lower and upper boundary of reaction rate $x$.

In this study, we used the objective functions "maximize biomass yield" and "maximize ATP yield." Constraints were set on transport fluxes depending on whether a compound was consumed or produced. In case a rate was measured, the transport rate was constrained to the measured value. Reactions that are irreversible were constrained to one direction. To solve the underdetermined parts, constraints were set in such a way that flux distributions that are thermodynamically impossible were excluded.

Mathcad 14.0 (M020, Parametric Technology Corporation, USA) was used for network analysis, and Matlab (version 6.0.0.88, release 12, The MathWorks Inc., USA) was used for in silico simulations.

\section{Theoretical aspects—energy parameters}

The ATP balance for complete metabolic network models can be written as Eq. 4:

$q_{\text {ATP }, \text { ox }}+q_{\text {ATP }, \text { light }}+\sum q_{i}^{\text {ATP }}-K_{x} \cdot \mu-m_{\text {ATP }}=0$

In this balance, the first term, $q_{\mathrm{ATP}, \mathrm{ox}}\left(\mathrm{mmol} \mathrm{g}^{-1} \mathrm{~h}^{-1}\right)$, is the specific ATP production rate in oxidative phosphorylation in the mitochondria. The second term, $q_{\text {ATP,light }}\left(\mathrm{mmol} \mathrm{g}^{-1} \mathrm{~h}^{-1}\right)$, represents sum of the specific ATP production rate in the light reaction in the chloroplast. The third term, $\sum q_{i}{ }^{\text {ATP }}$ $\left(\mathrm{mmol} \mathrm{g}^{-1} \mathrm{~h}^{-1}\right)$, is the specific ATP production and consumption in the part of the metabolism that has a known ATP stoichiometry. Notably, the synthesis reactions of the biopolymers that make up biomass have a known ATP stoichiometry and are, therefore, included in this term. The energy requirements for the formation of protein, DNA, RNA, and chlorophyll were assumed to be 4.306, 1.372, 0.4, and $2.0 \mathrm{~mol}$ ATP per mol of the respective macromolecule (Berg et al. 2003; http://www.kegg.com). The specific ATP consumption rate required to assemble these biopolymers into functional growing biomass does not have a fixed stoichiometry and is represented by the fourth term in the ATP balance equation. In this term, $\mu\left(\mathrm{h}^{-1}\right)$ is the specific growth rate and $K_{x}\left(\mathrm{mmol}^{-1}\right)$ is a constant, which represents the additional amount of ATP needed to make biomass from biopolymers, by others defined as the "growth-associated maintenance" (Kayser et al. 2005; Taymaz-Nikerel et al. 2010). This parameter $K_{x}$ also represents the energy needed for other processes which can be present in the cell and cannot be quantified separately, such as the Carbon Concentrating Mechanism and ATP use for nutrient transport. Finally, the fifth term represents the maintenance ATP requirement, $m_{\text {ATP }}\left(\mathrm{mmol} \mathrm{g}^{-1} \mathrm{~h}^{-1}\right)$, which vary with the type of organism and the culture conditions.

The specific ATP production rate in the mitochondria depends on the $\mathrm{P} / \mathrm{O}$ ratio, which represents the amount of ATP formed per oxygen atom that is reduced. Here, we assume a constant $\mathrm{P} / \mathrm{O}$ ratio of 2.5 for $\mathrm{NADH}$ and 1.5 for $\mathrm{FADH}_{2}$. The stoichiometry of the light reaction also depends on environmental conditions. Here, we assume a 
fixed stoichiometry of two NADPH and three ATP generated per eight photons entering the photosynthetic machinery. With these two assumptions, all reactions contained in the first three terms have a fixed stoichiometry. The ATP balance (Eq. 4) thus shows that the sum of these three terms (hereafter " $q_{\text {ATP }}$ ") must be equal to the amount of ATP required for maintenance and for biomass formation from biopolymers.

The parameters $K_{x}$ and $m_{\text {ATP }}$ can be determined from experiments by determining $q_{\text {ATP }}$ at different growth rates. For this purpose, a series of chemostat cultures operated at different dilution rates were performed. By definition, the growth rate during steady state is equal to the dilution rate; thus, by setting different dilution rates, different growth rates can be studied. At steady state, the biomass density $\left(C_{x}, \mathrm{~g} \mathrm{~L}^{-1}\right)$ and the photon flux density absorbed by the algae ( PFD $\left._{\text {abs }}\right)$ were measured. With these values, a light supply rate per amount of biomass $\left(r_{\mathrm{Ex}}, \mathrm{mmol} \mathrm{g}^{-1} \mathrm{~h}^{-1}\right)$ can be calculated for each growth rate $\mu\left(\mathrm{h}^{-1}\right)$ according to Eq. 5:

$r_{\mathrm{Ex}}=\frac{\mathrm{PFD}_{\mathrm{abs}} \cdot A_{\mathrm{pbr}}}{\mathrm{C}_{x} \cdot V_{\mathrm{pbr}}}$

in which $\mathrm{PFD}_{\mathrm{abs}}$ is the absorbed photon flux density (in mmol photons $\mathrm{m}^{-2} \mathrm{~h}^{-1}$ in this equation), $A_{\mathrm{pbr}}$ is the illuminated surface of the photobioreactor $\left(\mathrm{m}^{2}\right)$ and $V_{\text {pbr }}$ the working volume of the photobioreactor (L).

At high irradiances, light saturation occurs and light energy is dissipated as heat and fluorescence, causing a decrease in the efficiency of the photosystems (Krause and Weis 1991; van der Tol et al. 2009). Consequently, the actual rate with which photons are used in algal metabolism is not known. Moreover, elevated irradiances also induce damage to the algal cells (Kok 1955), possibly increasing the energy consumption for maintenace purposes. $C$. reinhardtii becomes light saturated at irradiances of $300 \mu \mathrm{mol}$ photons $\mathrm{m}^{-2} \mathrm{~s}^{-1}$ (Janssen et al. 2000). At irradiances below $100 \mu \mathrm{mol}$ photons $\mathrm{m}^{-2} \mathrm{~s}^{-1}$, light energy is limiting and is used at maximal efficiency as can be deduced from the fact that the growth curve increases linearly with irradiances below this level (Janssen et al. 2000). The model only considers photons that are taken up for photosynthesis because dissipation and other effects were not modeled. Hence, the chemostat experiments to estimate the energy parameters for the metabolic model were performed at low irradiances $\left(<100 \mu \mathrm{mol}\right.$ photons $\left.\mathrm{m}^{-2} \mathrm{~s}^{-1}\right)$ to ensure that the photosystems were working at maximum efficiency and to prevent any light damage to the algal cells. However, even at low irradiances, not all light is taken up by the photosystem; therefore, the calculated light supply rate $r_{\mathrm{Ex}}$ should be corrected for the maximum efficiency $\left(\Phi_{\mathrm{P} \max }\right)$ of the photosystems. $\Phi_{\mathrm{P} \max }$ was assumed to be 0.8 , which corresponds to a quantum requirement of oxygen evolution of 10 (instead of 8 according to the Z-scheme). This is in accordance with measurements of the quantum requirement under ideal low light conditions for a variety of organisms using a variety of experimental techniques (Bjorkman and Demmig 1987; Dubinsky et al. 1986; Emerson and Lewis 1943; Evans 1987; Ley and Mauzerall 1982; Malkin and Fork 1996; Tanada 1951). The specific light utilization rate $\left(r_{\mathrm{Ex}, \mu}\right.$ in mmol photons $\mathrm{g}^{-1} \mathrm{~h}^{-1}$ ), which is the rate with which light is used to generate ATP and NADPH, can now be calculated according to Eq. 6:

$r_{\mathrm{Ex}, \mu}=\Phi_{\mathrm{Pmax}} \cdot r_{\mathrm{Ex}}$

With the specific light utilization rate $r_{\mathrm{Ex}}$ and the specific growth rate $\mu$ as input for the metabolic model, $q_{\text {ATP }}$ can be calculated for each different growth rate. Since the composition of the biomass can have a significant effect on the flux distribution in the model (Pramanik and Keasling 1998) and thus on $q_{\mathrm{ATP}}$, the biomass composition was measured for each steady state and also used as input for the model. The $q_{\mathrm{ATP}}$ was calculated by setting $K_{x}$ to zero in the overall biomass formation reaction (reaction 147). From Eq. 4, it can be seen that $q_{\mathrm{ATP}}$ is now equal to the maintenance term. In the metabolic model, maintenance is represented as the hydrolysis of ATP in reaction 57 of the model. Thus, by maximizing the flux through this reaction, using the specific light utilization rate, the specific growth rate, and the biomass composition as input, the amount of ATP that is produced in the part of the network which has a known stoichiometry, $q_{\mathrm{ATP}}$, can be calculated for each steady state. Subsequently, we can determine $K_{x}$ and $m_{\mathrm{ATP}}$ by plotting $q_{\text {ATP }}$ as a function of the specific growth rate $\mu$. The slope of this line, obtained by linear regression, represents $K_{x}$ and the intercept represents $m_{\mathrm{ATB}}$, according to Eq. 4. Note that setting $K_{x}$ to zero and maximizing the flux through the ATP hydrolysis reaction is just a method to calculate the ATP production rate. To complete the metabolic model with the correct energy requirements for biomass formation and maintenance, the value for $K_{x}$ has to be incorporated in the biomass synthesis reaction (reaction 147) after conversion to the appropriate units $\left(\mathrm{mol} \mathrm{mol}^{-1}\right)$. The maintenance ATP requirement is incorporated by constraining the ATP hydrolysis reaction to the value of $m_{\text {ATP }}$.

\section{Results and discussion}

Metabolic network construction

A metabolic network describing the primary metabolism of C. reinhardtii was constructed based on literature (Berg et al. 2003; Boyle and Morgan 2009; Cogne et al. 2003; 
Harris 2009; Yang et al. 2000) and the KEGG database (Kanehisa and Goto 2000; http://www.kegg.com). We cross-checked the model with the genome of $C$. reinhardtii (Merchant et al. 2007) to ensure the presence of the enzymes catalyzing the modeled reactions. In this model, we described two cell compartments, the chloroplast and the cytosol, to be able to uncouple the Calvin cycle, the PPP, and the production and consumption of NADPH. For the light reaction, only linear electron transport was modeled.

A large network with over 300 enzymatic reactions was obtained. This extensive model was reduced to a smaller, more practical network. This was done by lumping linear pathways into one reaction equation. The resulting network contains 160 reactions and 164 compounds and is listed in Appendix A. A simplified overview of this metabolic network is shown in Fig. 2.

We found that several enzymatic steps which were necessary in the network were not annotated in the KEGG database. Therefore, we performed protein basic local alignment search tool (BLAST) (Altschul et al. 1990) searches against the $C$. reinhardtii genome, using amino acid sequences from green (micro)organisms for the "missing" enzymes. Appendix C shows the enzymes, the E.C. numbers, and the corresponding geneIDs that were found in this way. The reactions in the network (partly) catalyzed by these enzymes are also given. In total, 41 enzymes were found not to be annotated in the KEGG database, of which 39 were retrieved by BLAST searches. Of these 39 enzymes, several have a geneID and are annotated but are not taken up in the KEGG database yet. Other enzymes have a draft geneID and still need to be annotated.

Only two enzymes could not be found in this way. The first one is ATP phosphoribosyltransferase (E.C. 2.4.2.17). This enzyme is essential in histidine formation and is described in the Chlamydomonas Sourcebook (Harris 2009). The second enzyme is homoserine acetyltransferase (E.C. 2.3.1.31), which is necessary in cysteine formation. This enzyme is present in other green microalgae (Ostreococcus lucimarinus), cyanobacteria (Synechococcus elongates, Anabaena variabilis), and diatoms (Phaeodactylum tricornutum, Thalassiosira pseudonana). BLAST searches with the amino acid sequences from these organisms did not give a result. Therefore, we assume this reaction is performed by another but similar enzyme because this step is essential in the formation of cysteine. Because both histidine and cysteine were measured in the amino acid composition and not added to the medium, they had to be formed within the metabolism. Thus, both reactions were taken up in the model.

By studying the null space of matrix $A_{\mathrm{c}}$ (Eq. 2), 12 underdetermined parts were revealed in the model. This means that there is no unique solution for Eq. 2. By measuring and setting constraints to some of the fluxes in

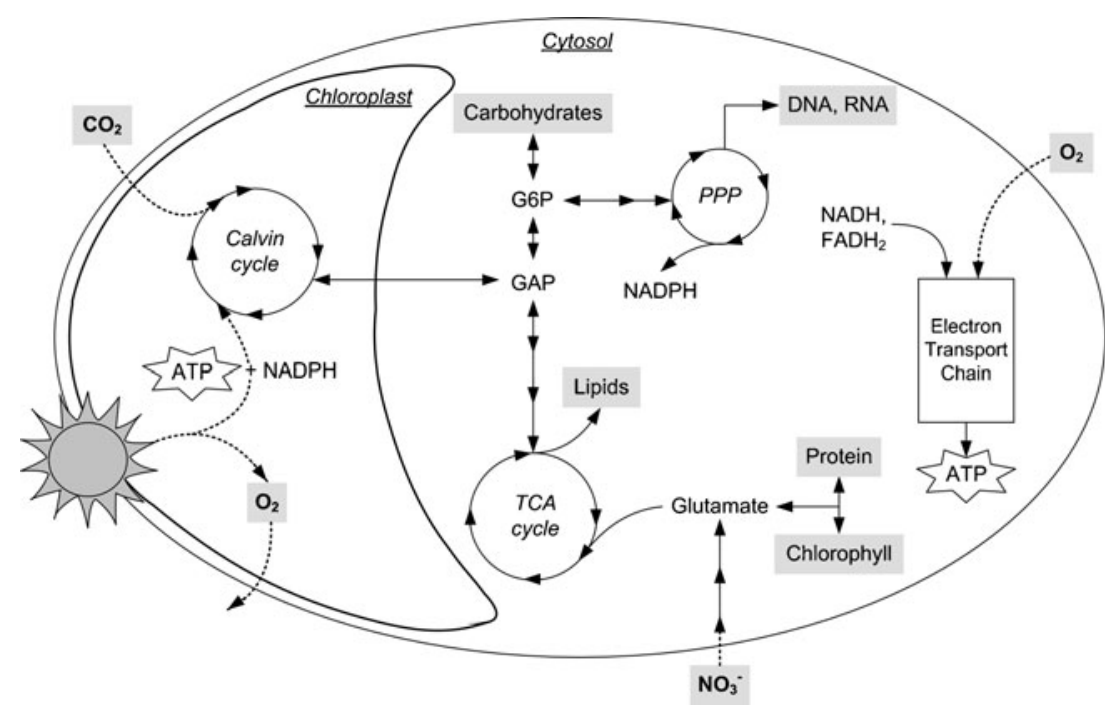

Fig. 2 Overview of an algal cell in the light, showing the main metabolic processes. Only the chloroplast and the cytosol were modeled as cell compartments; therefore, mitochondrial processes such as respiration through the electron transport chain were placed in the cytosol. Light is fixed in the chloroplast, yielding $\mathrm{O}_{2}$, ATP, and NADPH. These are needed for the fixation of carbon dioxide in the Calvin cycle into glyceraldehyde 3-phosphate $(G A P)$. GAP can be transported to the cytosol to be converted into building blocks for biomass. Lipids are formed through glycolysis and the tricarboxylic acid (TCA) cycle. Nitrate is taken up by the cell and converted into glutamate which in turn can be converted to protein and chlorophyll. GAP can be converted to glucose 6-phosphate (G6P) from which carbohydrates are formed. G6P can also enter the pentose phosphate pathway (PPP) which yields NADPH, DNA and RNA. Electrons are carried by NADH and $\mathrm{FADH}_{2}$ to the mitochondrial electron transport chain, yielding ATP by taking up $\mathrm{O}_{2}$ 
the underdetermined parts of the metabolism and using optimization of objective functions, unique solutions could be obtained. Reactions that are irreversible were constrained to one direction, and thermodynamically impossible combinations of reactions were also constrained in the correct direction. In the appendix, the arrows indicate whether a reaction is reversible or irreversible and if so, in which direction it is set. By choosing the objective functions "maximize biomass yield" and "maximize ATP yield" unique values could be calculated for the fluxes in all but two underdetermined parts. The first remaining underdeterminancy involved the anaplerotic routes between phosphoenolpyruvate, pyruvate, and oxaloacetate. This was solved by setting the upper and lower boundaries of the flux through reaction 35 to 0 . The second underdetermined part involved the coupling of the PPP, the glycolysis, and the tricarboxylic acid cycle (TCA). The aerobic degradation of sugars can occur through both the PPP as well as the TCA if NADPH and NADH are freely exchangeable through reaction 54, a transhydrogenase reaction. We restricted this by setting this reaction forward so NADPH can only be converted to NADH. In this way, the fluxes through the PPP will only be dictated by the demand of NADPH and PPP intermediates.

\section{Chemostat experiments}

To estimate the energy parameters for maintenance and the formation of biomass, we performed seven chemostat experiments at low irradiances and low dilution rates ranging from 0.018 to $0.064 \mathrm{~h}^{-1}$. The experiments were performed at irradiances to make sure the photosystems were working at maximum efficiency (Baker et al. 2007) and to prevent light damage to the algal cells. When steady state was reached, the biomass density $C_{x}\left(\mathrm{~g} \mathrm{~L}^{-1}\right)$ and the photon flux density absorbed by the algae $\left(\mathrm{PFD}_{\mathrm{abs}}\right)$ were measured for each dilution rate. In Table 2, the biomass density and the $\mathrm{PFD}_{\mathrm{abs}}$ at the different growth rates are given as well as the residence time for each steady state. With the biomass density and the photon flux density values, a light supply rate per amount of biomass $\left(r_{\mathrm{Ex}}\right.$, mmol g ${ }^{-1} \mathrm{~h}^{-1}$ ) could be calculated for each growth rate $\mu$ $\left(\mathrm{h}^{-1}\right)$ according to Eq. 5. The relationship between the specific light supply rate $r_{\mathrm{Ex}}\left(\mathrm{mmol}\right.$ photons $\mathrm{g}^{-1} \mathrm{~h}^{-1}$ ) and the growth rate $\mu\left(\mathrm{h}^{-1}\right)$ can be described using the model of Pirt (1965) as used by Zijffers et al. (2010) according to Eq. 7:

$r_{\mathrm{Ex}}=\frac{\mu}{Y_{x E}}+m_{E}$

in which $m_{E}$ is the maintenance requirement (mmol photons $\mathrm{g}^{-1} \mathrm{~h}^{-1}$ ) and $Y_{x E}$ the yield of biomass on light (g biomass mmol photons ${ }^{-1}$ ). The amount of light used by the algae increases proportionally to the growth rate while a fixed amount of maintenance light energy is necessary to keep the algae in a healthy state. Regression on the specific growth rates $\mu$ and specific light supply rates $r_{\mathrm{Ex}}$ for all chemostat experiments yields a straight line with a $R^{2}$ of 0.989. According to Eq. 7, the offset of this line gives a $m_{E}$ of $5.98 \pm 1.63 \mathrm{mmol} \mathrm{gh}^{-1}$ and the inverse of the slope gives an $Y_{x E}$ of $1.25 \pm 0.06 \mathrm{~g} \mathrm{~mol}^{-1}$. This $Y_{x E}$ is high compared to biomass yields found for other green microalgae as can be seen from Table 3. Cuaresma et al. (2009), Kliphuis et al. (2010b), and Zijffers et al. (2010) found yields ranging from 0.5 to $1.0 \mathrm{~g} \mathrm{~mol}^{-1}$ for several green microalgae. These yields were all obtained at high irradiances of $1,000 \mu \mathrm{mol}$ photons $\mathrm{m}^{-2} \mathrm{~s}^{-1}$ or more. At low irradiances, we expect a higher yield than at high irradiances because at high irradiances, the antenna complexes in the algal photosystems become saturated. The remainder of the absorbed light will be dissipated as heat or fluorescence (Krause and Weis 1991; van der Tol et al. 2009). In addition, elevated irradiances also induce damage to the algal cells (Kok 1955), possibly increasing the energy consumption for maintenance purposes. Therefore, high irradiances will lead to low photosynthetic efficiencies as can also be seen from the yields for C. reinhardtii obtained by Takache et al. (2010). The difference between the yields at high and low irradiances in these experiments reflects the fact that a large part of
Table 2 Biomass density, absorbed photon flux density, and growth rates determined for each chemostat experiment

The residence time is calculated as $1 / \mu$ for each steady state. The specific light utilization rate is calculated from these data using Eq. 5 and 6. Mean \pm standard deviation

${ }^{\text {a }} N=13,4,6,7,13,6,8$, respectively

${ }^{\mathrm{b}} N=8,3,6,5,5,4,4$, respectively

\begin{tabular}{llllc}
\hline $\begin{array}{l}\text { Growth rate } \\
\mu\left(\mathrm{h}^{-1}\right)\end{array}$ & $\begin{array}{l}\text { Residence } \\
\text { time }^{\mathrm{a}}(\mathrm{h})\end{array}$ & $\begin{array}{l}\text { Biomass density } \\
C_{x}^{\mathrm{b}}\left(\mathrm{g} \mathrm{L}^{-1}\right)\end{array}$ & $\begin{array}{l}\text { Photon flux density } \\
\text { absorbed PFD } \\
\left(\mu \text { mol photons } \mathrm{m}^{-2} \mathrm{~s}^{-1}\right)\end{array}$ & $\begin{array}{l}\text { Specific light } \\
\text { utilization rate } r_{\text {Ex }, \mu} \\
\left(\text { mmol photons g }^{-1} \mathrm{~h}^{-1}\right)\end{array}$ \\
\hline $0.018 \pm 0.000$ & $55.1 \pm 0.5$ & $0.78 \pm 0.04$ & 88 & $15.8 \pm 0.8$ \\
$0.019 \pm 0.000$ & $52.8 \pm 1.2$ & $0.84 \pm 0.08$ & 87 & $16.7 \pm 1.5$ \\
$0.031 \pm 0.001$ & $32.3 \pm 1.0$ & $0.41 \pm 0.02$ & 80 & $25.7 \pm 1.4$ \\
$0.034 \pm 0.001$ & $29.7 \pm 1.1$ & $0.39 \pm 0.02$ & 73 & $26.8 \pm 1.6$ \\
$0.052 \pm 0.001$ & $19.3 \pm 0.5$ & $0.21 \pm 0.01$ & 51 & $36.1 \pm 1.7$ \\
$0.061 \pm 0.003$ & $16.5 \pm 0.7$ & $0.11 \pm 0.01$ & 36 & $45.5 \pm 3.7$ \\
$0.064 \pm 0.001$ & $15.6 \pm 0.0$ & $0.10 \pm 0.01$ & 31 & $44.8 \pm 3.7$ \\
\hline
\end{tabular}


Table 3 Comparison of biomass yields on light energy and the used irradiances for different microalgae from literature

\begin{tabular}{llll}
\hline Organism & $Y_{x E}$ or $Y_{x E}{ }^{\text {obs }}\left(\mathrm{g} \mathrm{mol}^{-1}\right)$ & Light intensity $\left(\mu \mathrm{mol}\right.$ photons $\left.\mathrm{m}^{-2} \mathrm{~s}^{-1}\right)$ & Reference \\
\hline Chlamydomonas reinhardtii & $1.25 \pm 0.06^{\mathrm{a}, \mathrm{d}}$ & 80 & This paper \\
Dunaliella tertiolecta & $0.78^{\mathrm{a}}$ & 930 & Zijffers et al. (2010) \\
Chlorella sorokiniana & $0.75^{\mathrm{a}}$ & 930 & Zijffers et al. (2010) \\
Chlorella sorokiniana & $0.80^{\mathrm{b}}$ & 1500 & Kliphuis et al. (2010b) \\
Chlorella sorokiniana & $1.0^{\mathrm{b}}$ & 2100 & Cuaresma et al. (2009) \\
Chlamydomonas reinhardtii & $1.11^{\mathrm{b}, \mathrm{c}}$ & 110 & Takache et al. (2010) \\
Chlamydomonas reinhardtii & $0.73^{\mathrm{b}, \mathrm{c}}$ & 500 & Takache et al. (2010) \\
Chlamydomonas reinhardtii & $0.51^{\mathrm{b}, \mathrm{c}}$ & 1000 & Takache et al. (2010) \\
\hline
\end{tabular}

${ }^{\mathrm{a}} Y_{x E}=\mu /\left(\mathrm{r}_{\mathrm{Ex}}+\mathrm{m}_{\mathrm{E}}\right)$, according to Eq. 7

${ }^{\mathrm{b}} Y_{x E}{ }^{\mathrm{obs}}=\mu / r_{\mathrm{Ex}}$ (the observed yield was not corrected for maintenance requirements)

${ }^{\mathrm{c}}$ Recalculated from data obtained in flat Torus photobioreactor by Takache et al. (2010)

${ }^{\mathrm{d}}$ Calculated by linear regression $(P<0.05)$

the light is "wasted" at higher irradiances. The high biomass yield found in our experiments supports the hypothesis that the efficiency of the algal photosystems was indeed high at a light intensity of $80 \mu \mathrm{mol}$ photons $\mathrm{m}^{-2} \mathrm{~s}^{-1}$. Moreover, it seems that we were working at maximal efficiency because the relation between specific light utilization and specific growth rate is linear $\left(R^{2}=\right.$ 0.988 ). This shows that the biomass yield is constant and not influenced by the change in light regime (Table 2), indicating we reached the maximal value of this yield parameter. Furthermore, it also shows that photorespiration, which results in waste of ATP, is negligible.

It needs to be stressed that even at these low irradiances, not all absorbed light can be converted in the photosystems. Therefore, the light supply rate $r_{\mathrm{Ex}}$ was corrected for the maximum efficiency $\left(\Phi_{\mathrm{P} \max }=0.8\right)$ of the photosystems to obtain the specific light utilization rate $r_{\mathrm{Ex}, \mu}$ (Eq. 6), which is also shown in Table 2. This specific light utilization rate $r_{\mathrm{Ex}, \mu}$ should be used for energy parameter estimation, since this rate represents the actual amount of photons that enter the algal metabolism. As expected, regression on the specific growth rates $\mu$ and specific light utilization rates $r_{\mathrm{Ex}, \mu}$ also yields a straight line according to Eq. 7. The offset of this line gives $m_{E}$ of $4.79 \pm 1.31 \mathrm{mmol} \mathrm{g}^{-1} \mathrm{~h}^{-1}$ and the inverse of the slope gives $Y_{x E}$ of $1.57 \pm 0.07 \mathrm{gmol}^{-1}$. These values represent the yield and maintenance requirements corrected for the inefficiency of light use, $\Phi_{\mathrm{P} \max }$.

\section{Biomass composition}

The composition of the biomass can have a significant effect on the flux distribution in the model and thus on the estimation of energy parameters (Pramanik and Keasling 1998). Therefore, the macromolecular biomass composition $(\% w / w)$ was determined for six of the steady states as shown in Table 4. In addition, the average biomass composition for all growth rates is given here. These compositions, along with the corresponding growth rates $\mu$ and light utilization rates $r_{\mathrm{Ex}, \mu}$, were used for the model simulation of each steady state. The macromolecular biomass composition was not measured for $\mu=0.019 \mathrm{~h}^{-1}$; therefore, the composition of $\mu=0.018 \mathrm{~h}^{-1}$ was used to perform model simulations for this growth rate.

The biomass composition did not show much variation as a function of growth rate, although the carbohydrate content seemed to increase at increasing growth rates. The pigment content, on the other hand, decreased at increasing growth rate, which can be explained by the fact that the amount of light per cell increased at increasing growth rate, because the culture became more diluted. Such a response of microalgae to decrease the amount of photosynthetic pigments upon an increase in irradiance is known as photoacclimation (Dubinsky and Stambler 2009). Protein, nucleic acids, and ash content did not vary significantly. Since the composition of the biomass did not change very much in this range of growth rates, the average biomass composition was used in the final model.

In Appendix D, the elemental composition of all macromolecules and of the $C$. reinhardtii biomass itself is given. The amino acid composition and the average fatty acid composition can be found in Appendixes $\mathrm{E}$ and $\mathrm{F}$.

Energy requirements for growth and maintenance

Using the specific growth rate $\mu$, the specific light utilization rate $r_{\mathrm{Ex}, \mu}$ (Table 2) and the biomass composition as determined for each steady state (Table 4) as input for the model, $q_{\text {ATP }}$ can be calculated as described in the Theoretical aspects section. Figure 3 shows the plot of $q_{\text {ATP }}$ against the specific growth rate, $\mu$. Linear regression through these 
Table 4 Measured biomass composition ( $\%$ w/w) normalized to $100 \%$ and average biomass composition of C. reinhardtii at different specific growth rates (mean \pm standard deviation)

\begin{tabular}{llllllll}
\hline & \multicolumn{1}{l}{$\mu\left(\mathrm{h}^{-1}\right)$} & & Average $^{c}$ \\
\cline { 2 - 7 } & 0.018 & 0.031 & 0.034 & 0.052 & 0.061 & 0.064 \\
\hline Protein $^{\mathrm{a}}$ & $42.48 \pm 0.55$ & $39.34 \pm 0.77$ & $40.17 \pm 1.10$ & $41.63 \pm 0.67$ & $40.16 \pm 0.40$ & $37.61 \pm 0.88$ & $40.23 \pm 1.71$ \\
Carbohydrate $^{\mathrm{a}}$ & $24.09 \pm 2.00$ & $21.70 \pm 0.73$ & $24.62 \pm 2.15$ & $27.29 \pm 4.08$ & $26.26 \pm 1.59$ & $28.87 \pm 1.11$ & $25.47 \pm 2.54$ \\
Lipids $^{\text {a }}$ & $14.13 \pm 0.28$ & $22.16 \pm 2.24$ & $17.72 \pm 0.88$ & $14.25 \pm 0.47$ & $16.78 \pm 3.85$ & $18.65 \pm 1.84$ & $17.28 \pm 3.01$ \\
DNA $^{\mathrm{b}}$ & $0.21 \pm 0.008$ & $0.20 \pm 0.004$ & $0.23 \pm 0.006$ & $0.22 \pm 0.002$ & $0.23 \pm 0.002$ & $0.19 \pm 0.002$ & $0.21 \pm 0.02$ \\
RNA $^{\mathrm{b}}$ & $5.99 \pm 0.23$ & $5.57 \pm 0.12$ & $6.48 \pm 0.16$ & $6.04 \pm 0.06$ & $6.57 \pm 0.06$ & $5.27 \pm 0.05$ & $5.99 \pm 0.50$ \\
Chlorophyll $^{\text {a }}$ & $7.06 \pm 0.07$ & $5.59 \pm 0.03$ & $5.13 \pm 0.05$ & $4.73 \pm 0.07$ & $4.34 \pm 0.20$ & $4.01 \pm 0.06$ & $5.14 \pm 1.09$ \\
Ash $^{\text {a }}$ & $6.05 \pm 0.03$ & $5.44 \pm 0.40$ & $5.66 \pm 0.24$ & $5.84 \pm 0.11$ & $5.66 \pm 0.24$ & $5.41 \pm 0.42$ & $5.68 \pm 0.24$ \\
\hline
\end{tabular}

The sum of the individual biomass components including ash was comparable to the measured dry weights within $10 \%$

${ }^{\mathrm{a}} N=3$ for each steady state

${ }^{\mathrm{b}}$ Based on literature values (Merchant et al. 2007; Valle et al. 1981) and the measured dry weight and cell numbers. $N=3,6,5,5,4,8$, respectively

${ }^{\mathrm{c}}$ Average biomass composition for all growth rates with the standard deviation for all six growth rates

points yields a straight line $(P<0.05)$. According to Eq. 4 , the offset of this line gives the ATP required for maintenance $\left(m_{\text {ATP }}\right)$, being $2.85 \pm 0.82 \mathrm{mmol} \mathrm{g}^{-1} \mathrm{~h}^{-1}$. The slope represents $K_{x}$, the amount of ATP needed to make biomass from biopolymers and has a value of $109 \pm 19 \mathrm{mmol} \mathrm{g}^{-1}$. From this number, it could be calculated that $18.9 \mathrm{~mol}$ ATP is required to transport and assemble 1 mol biomass. This amount was added to the biomass synthesis reaction (mol ATP per mol biomass, reaction 147) of the final model. The ATP

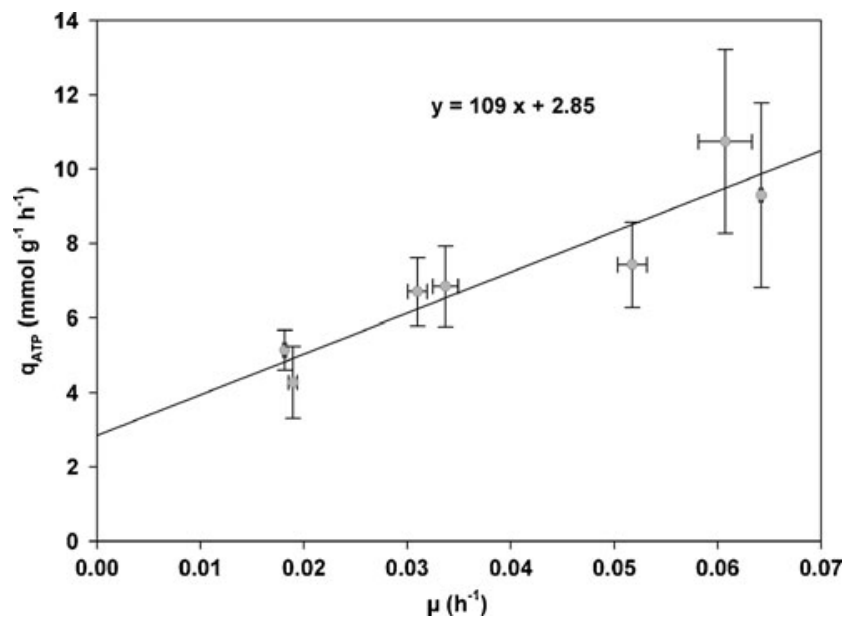

Fig. 3 Plot of the specific calculated overall ATP production rate $q_{\text {ATP }}$ against the experimentally determined growth rate. $q_{\text {ATP }}$ was calculated with the model for each growth rate. Regression through these points yields a straight line of which the offset gives the ATP required

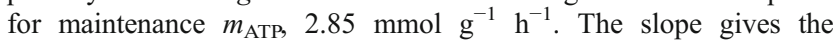
constant which represents the additional amount of ATP needed to make biomass from the biopolymers $\left(K_{x}\right), 109 \mathrm{mmol} \mathrm{g}^{-1}$, according to Eq. 4. The error bars represent the minimum and maximum values for $q_{\text {ATP }}$ and the growth rate $\mu$, which follow from the relative errors of biomass measurements hydrolysis flux (reaction 57) was set to the value for $m_{\mathrm{ATP}}$ to fix the maintenance requirements of the final metabolic model.

An overview of values for $K_{x}$ and $m_{\mathrm{ATP}}$ for several microorganisms is presented in Table 5. The value for $K_{x}$ depends on the characteristics of the model, for example the degree of compartmentalization and the ATP stoichiometry for biopolymer formation and thus the value for $K_{x}$ differs per model. To make a good comparison of the total ATP use in several species, $1 / Y_{x \text { ATP }}\left(\mathrm{mol} \mathrm{ATP} \mathrm{g}^{-1}\right.$ ) is also given, which is the total amount of ATP required to make $1 \mathrm{~g}$ of biomass. As can be seen from Table 5, there is considerable variation in the values for $1 / Y_{x \mathrm{ATP}}, K_{x}$, and $m_{\mathrm{ATP}}$ for different microorganisms. This can be due to the type of microorganism, the culture conditions, and the assumptions made in the models.

Firstly, these parameters depend on the assumed $\mathrm{P} / \mathrm{O}$ ratio, the relationship between ATP synthesis, and oxygen consumption. We assumed that NADH yields 2.5 ATP and $\mathrm{FADH}_{2}$ yields 1.5 ATP upon respiration. However, lower values for these ratios would result in lower values for $K_{x}$ and $m_{\text {ATP. }}$

Secondly, we assumed a ratio between NADPH and ATP production during linear electron transport in chloroplast of 3:2 (ATP/NADPH) which exactly fits the requirements of the Calvin cycle. Studies on Spinach chloroplasts, however, show that linear electron transport only can deliver 2.57 ATP per every two NADPH and that cyclic photosynthetic electron transport (i.e., cyclic photophosphorylation) is needed to generate additional ATP (Allen 2003). This cyclic pathway was not included in our model because the additional ATP requirement is small, and it would make our model underdetermined. Its necessity, however, could partly explain the fact that the experimentally determined 
Table 5 Comparison of yields and maintenance coefficients of different microorganisms from literature

${ }^{\text {a }}$ Photoautotrophic growth on light and $\mathrm{CO}_{2}$

${ }^{\mathrm{b}}$ Heterotrophic growth on glucose. Glucose yields 32 ATP (Berg et al. 2003)

${ }^{\mathrm{c}}$ Values are given \pm their standard error as calculated by linear regression $(P<0.05)$

\begin{tabular}{|c|c|c|c|c|}
\hline Organism & $\begin{array}{l}1 / Y_{x \mathrm{ATP}} \\
\left(\mathrm{mol} \mathrm{g}^{-1}\right)\end{array}$ & $K_{x}\left(\mathrm{~mol} \mathrm{~g}^{-1}\right)$ & $\begin{array}{l}m_{\text {ATP }} \\
\left(\mathrm{mmol} \mathrm{g}{ }^{-1} \mathrm{~h}^{-1}\right)\end{array}$ & Reference \\
\hline Chlamydomonas reinhardtii ${ }^{\mathrm{a}}$ & 0.43 & $0.11 \pm 0.018^{\mathrm{c}}$ & $2.85 \pm 0.82^{\mathrm{c}}$ & This paper \\
\hline Petunia hybrida (cell culture) $^{\mathrm{b}}$ & 0.44 & 0.15 & 1.41 & de Gucht and van der Plas (1995) \\
\hline Saccharomyces cerevisiae $^{\mathrm{b}}$ & 0.35 & 0.07 & 1.00 & Forster et al. (2003) \\
\hline Escherichia coli $^{\mathrm{b}}$ & 0.31 & 0.09 & 2.81 & Kayser et al. (2005) \\
\hline Escherichia coli $^{\mathrm{b}}$ & 0.40 & 0.10 & 4.70 & Carlson and Srienc (2004) \\
\hline Streptomyces coelicolor $^{\mathrm{b}}$ & - & 0.08 & 3.69 & Borodina et al. (2005) \\
\hline Neisseria meningitides ${ }^{\mathrm{b}}$ & 0.40 & 0.05 & 1.61 & Baart et al. (2008) \\
\hline Corynebacterium glutamicum $^{\mathrm{b}}$ & 0.29 & 0.03 & - & Kieldsen and Nielsen (2009) \\
\hline
\end{tabular}

minimal quantum requirement of oxygen evolution is 10 instead of 8 as discussed before (equivalent to $\Phi_{\mathrm{Pmax}}=0.8$ ) and as such, it is implicitly present in our model. Besides the balance of ATP and NADPH in the chloroplast, the microalgal cells as a whole require substantial ATP as is extensively discussed in this study. According to our model, ATP must be generated by the complete conversion of sugars (GAP) produced in the chloroplast by the combined action of glycolysis, TCA cycle, and oxidative phosphorylation in the cytosol and mitochondria (Fig. 2). It is interesting to note that this pathway ultimately yields $1 \mathrm{~mol}$ of ATP per $1.5 \mathrm{~mol}$ photons (see "Simulation of oxygen uptake through respiration" for calculation). Cyclic photophosphorylation, on the other hand, would only yield $1 \mathrm{~mol}$ of ATP per two photons (Allen 2003). This shows that energy generation through linear photosynthetic electron transport is energetically more favorable than through cyclic electron transport and supports our description of C. reinhardtii metabolism.

Thirdly, the parameter $K_{x}$ accounts for the requirement of ATP for biomass formation which is not accounted for in the part of the network with a known energy stoichiometry. For more complex models involving more compartmentalization, a larger part of the ATP may be accounted for, and consequently, the value of this parameter would become lower. However, for the two more extensive models described for Chlamydomonas, the energy parameters were not properly estimated. Manichaikul et al. (2009) used parameters taken from yeast cultivation and not from $C$. reinhardtii itself. Boyle and Morgan (2009) estimated the energy parameters for autotrophic, heterotrophic, and mixotrophic growth by fitting their model to one experimentally determined biomass yield, based on experiments performed in shake flasks. The maintenance parameter was taken from literature and not measured. Boyle and Morgan estimated a $K_{x}$ of $29.89 \mathrm{mmol} \mathrm{g}^{-1}$, which is indeed lower than our value, as would be expected for a more detailed model. However, they used shake flask experiments to estimate this parameter. Shake flasks usually have undefined light regimes, which makes it difficult to properly measure the absorbed light by the culture ( $\mathrm{PFD}_{\mathrm{abs}}$ ) and thus the light supply rate $\left(r_{\mathrm{Ex}}\right)$. Also, the efficiency of photosynthesis is unknown under these cultivation conditions. Furthermore, only a single growth rate was used, making the estimation highly dependent on the assumed value of the maintenance parameter.

\section{Simulation of oxygen uptake through respiration}

With the average biomass composition (Table 4) for all chemostats and the energy requirements for both maintenance and growth associated processes, a working model was obtained as shown in the appendix. With this model, we simulated the mitochondrial respiration rate $\left(\mathrm{mmol} \mathrm{O} \mathrm{O}^{-1} \mathrm{~h}^{-1}\right)$ at different growth rates $\left(\mu, \mathrm{h}^{-1}\right)$. Appendix $\mathrm{C}$ shows the flux distribution through the network at a specific growth rate $\mu$ of 0 and $0.062 \mathrm{~h}^{-1}$. The size of the fluxes in $\mathrm{mmol} \mathrm{g}^{-1} \mathrm{~h}^{-1}$ are shown in boxes, red boxes for $\mu=0 \mathrm{~h}^{-1}$ and black boxes for $\mu=0.062 \mathrm{~h}^{-1}$. Light is taken up in the light reaction of photosynthesis, and with the energy that is formed, $\mathrm{CO}_{2}$ is fixed in the Calvin cycle. The carbon is moved to the cytosol in the form of GAP, where it enters the glycolysis and TCA cycle. Part of the GAP is used to synthesize biopolymers and part is used here to generate energy in the form of ATP, NADH, and $\mathrm{FADH}_{2}$. NADH and $\mathrm{FADH}_{2}$ are in turn respired in the mitochondria to generate additional ATP to fulfill the energy requirements for growth and maintenance. The flux distribution at $\mu=0 \mathrm{~h}^{-1}$ shows the maintenance metabolism without biomass formation. It also shows that the minimal light uptake rate is $4.28 \mathrm{mmol}$ photons $\mathrm{g}^{-1} \mathrm{~h}^{-1}$, which is used to provide energy for maintenance ( $2.85 \mathrm{mmol}$ photons $\mathrm{g}^{-1} \mathrm{~h}^{-1}$ ). Using these fluxes, it can be calculated that in this model 1.5 mol photons should be consumed to produce 1 mol ATP.

Figure 4 shows the simulated biomass yield on light $\left(Y_{x E}\right.$ in $\mathrm{g} \mathrm{mol}^{-1}$, closed dots) for several growth rates $\mu$. These simulations give an ideal situation since no light saturation is modeled and consequently the biomass yield $Y_{x E}$ increases 


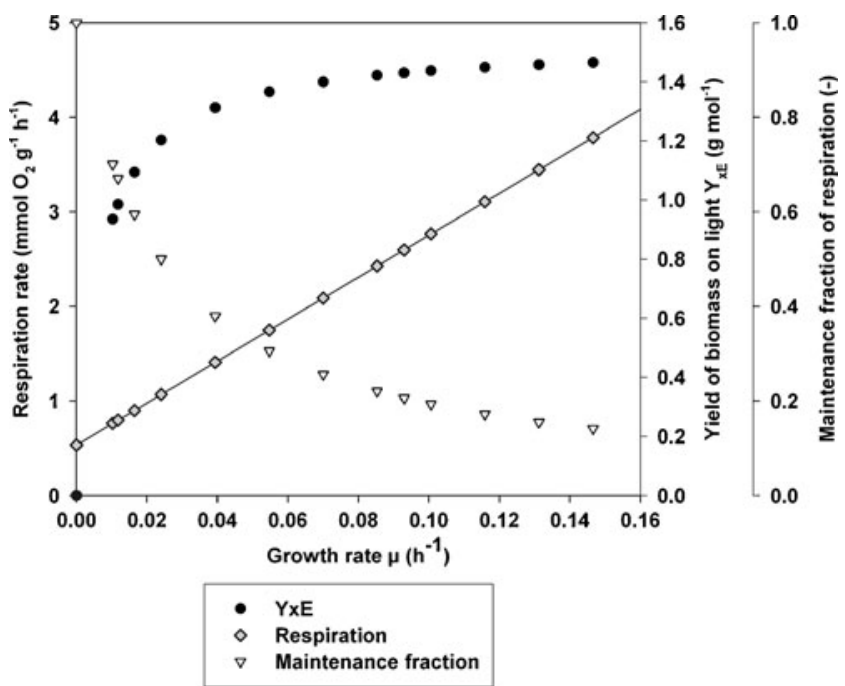

Fig. 4 Simulated respiration rates (mmol $\left.\mathrm{O}_{2} \mathrm{~g}^{-1} \mathrm{~h}^{-1}\right)$ at several growth rates $\left(\mu, \mathrm{h}^{-1}\right)$. Regression through these points yields a straight line with an intercept at $\mu=0$ of $0.53 \mathrm{mmol} \mathrm{O}_{2} \mathrm{~g}^{-1} \mathrm{~h}^{-1}$. This value is the oxygen uptake rate through respiration which is necessary for maintenance purposes. The maintenance fraction of the respiration rate is also plotted and shows which part of respiration is used for maintenance purposes. This graph also shows the simulated biomass yields on light energy $\left(Y_{x E}, \mathrm{~g} \mathrm{~mol}^{-1}\right)$ for these growth rates. The simulations give an ideal situation since light saturation is not modeled. If light saturation would be taken into account the yield would reach an optimum and decrease as soon as light saturation occurs

asymptotically to the maximal value of $1.57 \mathrm{gmol}^{-1}$ at very high specific growth rates. In reality, light saturation will occur due to the high irradiances necessary to reach maximal growth rates. The photons are absorbed, but the energy is only partly used for growth, causing a decrease in the biomass yield on light energy $\left(\Phi_{\mathrm{P}}<\Phi_{\mathrm{P} \max }\right.$, Eq. 6). If light saturation (Baker et al. 2007; Krause and Weis 1991; van der Tol et al. 2009) would be taken into account, the yield in Fig. 4 would reach an optimum and decrease as soon as light saturation occurs. The simulated respiration rate (open diamonds), calculated by the sum of the oxygen consumption rates in oxidative phosphorylation (reactions 52 and 53), and the fraction of oxygen used for maintenance (open triangles) are also plotted in Fig. 4. Respiration is a linear function of the growth rate. This is expected, since most ATP required for growth is generated by oxidation of GAP in the mitochondria. Regression through these points yields a straight line with an intercept of $0.53 \mathrm{mmol} \mathrm{O}_{2} \mathrm{~g}^{-1} \mathrm{~h}^{-1}$ at $\mu=0 \mathrm{~h}^{-1}$. This value is the oxygen uptake rate through respiration which is necessary for maintenance purposes. In earlier experimental work (Kliphuis et al. 2010a), we measured that the respiration rate required for maintenance for Chlorella sorokiniana was $0.3 \mathrm{mmol} \mathrm{O}_{2} \mathrm{~g}^{-1} \mathrm{~h}^{-1}$. This is in the same order as the value we now calculated for $C$. reinhardtii but almost twofold lower. As mentioned before, this is likely to be species-specific. It can be seen that at low growth rates, a relatively large part of respiration is needed for maintenance purposes. At high growth rates, the largest part of respiration is needed for energy generation for growth purposes. Consequently, cultivating microalgae at low specific growth rates results in a low biomass yield $Y_{x E}$, since a large part of the energy is used for maintenance processes rather than growth. This effect was experimentally confirmed for C. sorokiniana and Dunaliella tertiolecta by Zijffers et al. (2010).

\section{Conclusions}

A metabolic network describing the primary metabolism of $C$. reinhardtii was constructed. By performing chemostat experiments, energy parameters for maintenance and biomass formation were obtained. The chemostats were run at low irradiances resulting in a high biomass yield on light of $1.25 \mathrm{~g} \mathrm{~mol}^{-1}$. The ATP requirement for biomass formation from biopolymers $\left(K_{x}\right)$ was determined to be $109 \mathrm{mmol} \mathrm{g}^{-1}$ $\left(18.9 \mathrm{~mol} \mathrm{~mol}^{-1}\right)$, and the maintenance requirement $\left(m_{\text {ATP }}\right)$ was determined to be $2.85 \mathrm{mmol} \mathrm{g}^{-1} \mathrm{~h}^{-1}$. These values are in the same range as literature values. With these energy requirements included in the metabolic network, the network accurately describes the primary metabolism of $C$. reinhardtii and can be used for modeling of $C$. reinhardtii growth and metabolism. Simulations with this metabolic model confirmed that mitochondrial respiration both provides energy for maintenance and additional energy to support growth. The high maintenance requirements at low growth rates result in low biomass yields; thus, cultivating algae at low growth rates is unfavorable. Cultivating algae at high light supply rates is less favorable as well, because the biomass yield will decrease due to light saturation effects. Thus, to optimize biomass yield on light energy in photobioreactors, an optimum between these two situations should be found.

The simulations presented in this paper show that the metabolic model can be used as a tool to gain insight into the metabolism of $C$. reinhardtii and ultimately can be used for the maximization of biomass and product yield.

Acknowledgements This research project is financially supported by Technology Foundation STW-VICI (WLM.6622) and was performed in the TTIW-cooperation framework of Wetsus, center of excellence for sustainable water technology (www.wetsus.nl). Wetsus is funded by the Dutch Ministry of Economic Affairs. The authors like to thank the participants of the research theme 'algae' for their fruitful discussions and their financial support.

The authors declare that they have no conflict of interest. 
Open Access This article is distributed under the terms of the Creative Commons Attribution Noncommercial License which permits any noncommercial use, distribution, and reproduction in any medium, provided the original author(s) and source are credited.

\section{References}

Allen JF (2003) Cyclic, pseudocyclic and noncyclic photophosphorylation: new links in the chain. Trends Plant Sci 8(1):15-19

Altschul SF, Gish W, Miller W, Myers EW, Lipman DJ (1990) Basic local alignment search tool. J Mol Biol 215(3):403-410

Baart GJE, Willemsen M, Khatami E, Haan A, Zomer B, Beuvery EC, Tramper J, Martens DE (2008) Modeling Neisseria meningitidis $\mathrm{B}$ metabolism at different specific growth rates. Biotechnol Bioeng 101(5):1022-1035

Baker NR, Harbinson J, Kramer DM (2007) Determining the limitations and regulation of photosynthetic energy transduction in leaves. Plant Cell Environ 30(9):1107-1125

Ball SG, Dirick L, Decq A, Martiat J-C, Matagne RF (1990) Physiology of starch storage in the monocellular alga Chlamydomonas reinhardtii. Plant Sci 66(1):1-9

Becker EW (2007) Micro-algae as a source of protein. Biotechnol Adv 25(2):207-210

Ben-Amotz A, Katz A, Avron M (1982) Accumulation of $\beta$-carotene in halotolerant algae: purification and characterization of $\beta$ carotene-rich globules from Dunaliella bardawil (Chlorophyceae). J Phycol 18(4):529-537

Berg JM, Tymoczko JL, Stryer L (2003) Biochemistry. Freeman, New York

Bjorkman O, Demmig B (1987) Photon yield of $\mathrm{O}_{2}$ evolution and chlorophyll fluorescence characteristics at $77 \mathrm{~K}$ among vascular plants of diverse origins. Planta 170:489-504

Borodina I, Krabben P, Nielsen J (2005) Genome-scale analysis of Streptomyces coelicolor A3(2) metabolism. Gen Res 15(6):820 829

Bosma R, Miazek K, Willemsen SM, Vermuë MH, Wijffels RH (2008) Growth inhibition of Monodus subterraneus by free fatty acids. Biotechnol Bioeng 101(5):1108-1114

Boyd C (1968) Fresh-water plants: a potential source of protein. Econ Bot 22(4):359-368

Boyle NR, Morgan JA (2009) Flux balance analysis of primary metabolism in Chlamydomonas reinhardtii. BMC Syst Biol 3:4. doi:10.1186/1752-0509-1183-1184

Burgard AP, Vaidyaraman S, Maranas CD (2001) Minimal reaction sets for Escherichia coli metabolism under different growth requirements and uptake environments. Biotechnol Prog 17 (5):791-797

Carlson R, Srienc F (2004) Fundamental Escherichia coli biochemical pathways for biomass and energy production: Creation of overall flux states. Biotechnol Bioeng 86(2):149-162

Chisti Y (2007) Biodiesel from microalgae. Biotechnol Adv 25:294-306

Cogne G, Gros JB, Dussap CG (2003) Identification of a metabolic network structure representative of Arthrospira (Spirulina) platensis metabolism. Biotechnol Bioeng 84(6):667-676

Cuaresma M, Janssen M, Vílchez C, Wijffels RH (2009) Productivity of Chlorella sorokiniana in a short light-path (SLP) panel photobioreactor under high irradiance. Biotechnol Bioeng 104 (2):352-359

de Gucht LPE, van der Plas LHW (1995) Growth kinetics of glucoselimited Petunia hybrida cells in chemostat cultures: Determination of experimental values for growth and maintenance parameters. Biotechnol Bioeng 47(1):42-52
Delrue B, Fontaine T, Routier F, Decq A, Wieruszeski JM, Van Den Koornhuyse N, Maddelein ML, Fournet B, Ball S (1992) Waxy Chlamydomonas reinhardtii: monocellular algal mutants defective in amylose biosynthesis and granule-bound starch synthase activity accumulate a structurally modified amylopectin. J Bact 174 (11):3612-3620

Dubinsky Z, Stambler N (2009) Photoacclimation processes in phytoplankton: mechanisms, consequences, and applications. Aquat Micro Ecol 56(2-3):163-176

Dubinsky Z, Falkowski PG, Wyman K (1986) Light harvesting and utilization by phytoplankton. Plant Cell Physiol 27(7):1335-1349

Dubois M, Gilles KA, Hamilton JK, Rebers PA, Smith F (1956) Colorimetric method for determination of sugars and related substances. Anal Chem 28(3):350-356

Emerson R, Lewis CM (1943) The dependence of the quantum yield of Chlorella on wavelength of light. Am J Bot 30:165-178

Evans JR (1987) The Dependence of Quantum Yield on Wavelength and Growth Irradiance. Aus J Plant Physiol 14:69-79

Forster J, Famili I, Fu P, Palsson BO, Nielsen J (2003) Genome-scale reconstruction of the Saccharomyces cerevisiae metabolic network. Gen Res 13(2):244-253

Gfeller RP, Gibbs M (1984) Fermentative metabolism of Chlamydomonas reinhardtii: I. Analysis of fermentative products from starch in dark and light. Plant Physiol 75:212-218

Ghirardi ML, Zhang L, Lee JW, Flynn T, Seibert M, Greenbaum E, Melis A (2000) Microalgae: a green source of renewable $\mathrm{H}_{2}$. Trends Biotechnol 18(12):506-511

Griffiths MJ, Harrison STL (2009) Lipid productivity as a key characteristic for choosing algal species for biodiesel production. J App Phycol 21(5):493-507

Harris EH (2009) The Chlamydomonas sourcebook: a comprehensive guide to biology and laboratory use. Academic, San Diego

Heifetz PB, Förster B, Osmond CB, Giles LJ, Boynton E (2000) Effects of acetate on facultative autotrophy in Chlamydomonas reinhardtii assessed by photosynthetic measurements and stable isotope analyses. Plant Physiol 122(4):1439-1445

Herbert D, Phipps PJ, Strange RE (1971) Chemical analysis of microbial cells. In: Norris JR, Ribbons DW (eds) Methods in Microbiology. Academic, London, pp 209-344

Hu Q, Sommerfeld M, Jarvis E, Ghirardi M, Posewitz M, Seibert M, Darzins A (2008) Microalgal triacylglycerols as feedstocks for biofuel production: perspectives and advances. Plant J 54(4):621-639

Hutner SH, Provasoli L, Schatz A, Haskins CP (1950) Some approaches to the study of the role of metals in the metabolism of microorganisms. Proc Am Phil Soc 94(2):152-170

Janssen M, de Winter M, Tramper J, Mur LR, Snel JFH, Wijffels RH (2000) Efficiency of light utilization of Chlamydomonas reinhardtii under medium-duration light/dark cycles. JBiotechnol 78:123-137

Kanehisa M, Goto S (2000) KEGG: Kyoto Encyclopedia of Genes and Genomes. Nucl Acids Res 28(1):27-30

Kayser A, Weber J, Hecht V, Rinas U (2005) Metabolic flux analysis of Escherichia coli in glucose-limited continuous culture: I. Growth-rate dependent metabolic efficiency at steady state. Microbiol 151:693-706

Kieldsen KR, Nielsen J (2009) In silico genome-scale reconstruction and validation of the Corynebacterium glutamicum metabolic network. Biotechnol Bioeng 102(2):583-597

Kleinegris D, Janssen M, Brandenburg WA, Wijffels RH (2010) The Selectivity of Milking of Dunaliella salina. Mar Biotechnol 12:14-23

Kliphuis AMJ, Janssen M, van den End EJ, Martens DE, Wijffels RH (2010a) Light respiration in Chlorella sorokiniana. J App Phycol. doi:10.1007/s10811-010-9614-7 
Kliphuis AMJ, de Winter L, Vejrazka C, Martens DE, Janssen M, Wijffels RH (2010b) Photosynthetic efficiency of Chlorella sorokiniana in a turbulently mixed short light-path photobioreactor. Biotechnol Prog 26(3):687-696

Kok B (1955) On the inhibition of photosynthesis by intense light. Biochim Biophys Acta 21(2):234-244

Krause GH, Weis E (1991) Chlorophyll fluorescence and photosynthesis: The Basics. Ann Rev Plant Physiol Plant Mol Biol 42:313-349

Lamers PP, Janssen M, De Vos RCH, Bino RJ, Wijffels RH (2008) Exploring and exploiting carotenoid accumulation in Dunaliella salina for cell-factory applications. Trends Biotechnol 26 (11):631-638

Lamers PP, van de Laak CCW, Kaasenbrood PS, Lorier J, Janssen M, de Vos RCH, Bino RJ, Wijffels RH (2010) Carotenoid and fatty acid metabolism in light-stressed Dunaliella salina. Biotechnol Bioeng 106(4):638-648

Ley AC, Mauzerall D (1982) Absolute absorption cross-sections for photosystem II and the minimum quantum requirement for photosynthesis in Chlorella vulgaris. Biochim Biophys Acta 680:95-106

Lourenço SO, Barbarino E, Marquez UML, Aidar E (1998) Distribution of intracellular nitrogen in marine microalgae: basis for the calculation of specific nitrogen-to-protein conversionfactors. J Phycol 34(5):798-811

Malkin S, Fork DC (1996) Bill Arnold and calorimetric measurements of the quantum requirement of photosynthesis - once again ahead of his time. Photosynth Res 48:41-46

Manichaikul A, Ghamsari L, Hom EFY, Lin C, Murray RR, Chang RL, Balaji S, Hao T, Shen Y, Chavali AK, Thiele I, Yang X, Fan C, Mello E, Hill DE, Vidal M, Salehi-Ashtiani K, Papin JA (2009) Metabolic network analysis integrated with transcript verification for sequenced genomes. Nat Meth 6(8):589592

Melis A, Zhang L, Forestier M, Ghirardi ML, Seibert M (2000) Sustained photobiological hydrogen gas production upon reversible inactivation of oxygen evolution in the green alga Chlamydomonas reinhardtii. Plant Physiol 122(1):127-135

Merchant SS, Prochnik S, Vallon O, Harris EH, Karpowicz SJ, Witman GB, Terry A, Salamov A, Fritz-Laylin LK, Sanderfoot AA, Spalding MH, Kapitonov VV, Ren Q, Ferris P, Lindquist E, Shapiro H, Lucas S, Grimwood J, Schmutz J, Grigoriev IV, Rokhsar DS, Grossman AR (2007) The Chlamydomonas genome reveals the evolution of key animal and plant functions. Science 318:245-251

Pirt SJ (1965) The maintenance energy of bacteria in growing cultures. Proc Roy Soc B 163(991):224-231
Porra R (2002) The chequered history of the development and use of simultaneous equations for the accurate determination of chlorophylls a and b. Photosynth Res 73(1):149-156

Pottier L, Pruvost J, Deremetz J, Cornet JF, Legrand J, Dussap CG (2005) A fully predictive model for one-dimensional light attenuation by Chlamydomonas reinhardtii in a torus photobioreactor. Biotechnol Bioeng 91(5):569-582

Pramanik J, Keasling JD (1998) Effect of Escherichia coli biomass composition on central metabolic fluxes predicted by a stoichiometric model. Biotechnol Bioeng 60(2):230-238

Roels JA (1983) Relaxation times and their relevance to the construction of kinetic models. In: Verachtert H, de Mot R (eds) Energetics and kinetics in Biotechnology. Elsevier, Amsterdam, pp 205-221

Schmidt BJ, Lin-Schmidt X, Chamberlin A, Salehi-Ashtiani K, Papin JA (2010) Metabolic systems analysis to advance algal biotechnology. Biotechnol J 5(7):660-670

Stephanopoulos GN, Aristidou A, Nielsen J (1998) Metabolic Engineering, principles and methodologies. Academic, San Diego

Sueoka N, Chiang KS, Kates JR (1967) Deoxyribonucleic acid replication in meiosis of Chlamydomonas reinhardtii: I. Isotopic transfer experiments with a strain producing eight zoospores. $\mathrm{J}$ Mol Biol 25(1):47-66

Takache H, Christophe G, Cornet J-F, Pruvost J (2010) Experimental and theoretical assessment of maximum productivities for the microalgae Chlamydomonas reinhardtii in two different geometries of photobioreactors. Biotechnol Prog 26(2):431-440

Tanada T (1951) The photosynthetic efficiency of carotenoid pigments in Navicula minima. Am J Bot 38:276-283

Taymaz-Nikerel H, Borujeni AE, Verheijen PJ, Heijnen JJ, van Gulik WM (2010) Genome-derived minimal metabolic models for Escherichia coli MG1655 with estimated in vivo respiratory ATP stoichiometry. Biotechnol Bioeng 107(2):369-381

Valle O, Lien T, Knutsen G (1981) Fluorometric determination of DNA and RNA in Chlamydomonas using ethidium bromide. J Biochem Biophys Meth 4(5-6):271-277

van der Tol C, Verhoef W, Rosema A (2009) A model for chlorophyll fluorescence and photosynthesis at leaf scale. Agric For Meteo 149(1):96-105

Yang C, Hua Q, Shimizu K (2000) Energetics and carbon metabolism during growth of microalgal cells under photoautotrophic, mixotrophic and cyclic light-autotrophic/dark-heterotrophic conditions. Biochem Eng J 6(2):87-102

Zijffers JW, Schippers KJ, Zheng K, Janssen M, Tramper J, Wijffels RH (2010) Maximum photosynthetic yield of green microalgae in photobioreactors. Mar Biotechnol. doi:10.1007/s10126-010-9258-2 